"Perceived barriers to the development of small, medium and microenterprises: a case study of Thulamela Municipality in the Limpopo Province"

$\begin{array}{ll} & \text { Gift Donga } \\ \text { HUTHORS } & \text { Hnonganipai Ngirande } \\ \text { Knowledge Shumba }\end{array}$

Gift Donga, Hlanganipai Ngirande and Knowledge Shumba (2016). Perceived

ARTICLE INFO barriers to the development of small, medium and microenterprises: a case study of Thulamela Municipality in the Limpopo Province. Problems and Perspectives in Management, 14(4), 61-66. doi:10.21511/ppm.14(4).2016.07

DOI http://dx.doi.org/10.21511/ppm.14(4).2016.07

RELEASED ON Wednesday, 14 December 2016

JOURNAL "Problems and Perspectives in Management"

FOUNDER LLC "Consulting Publishing Company "Business Perspectives"

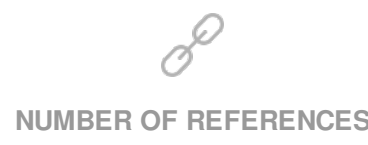

0
NUMBER OF FIGURES

0

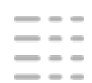

NUMBER OF TABLES

0

(C) The author(s) 2022. This publication is an open access article. 
Gift Donga (South Africa), Hlanganipai Ngirande (South Africa), Knowledge Shumba (South Africa)

\title{
Perceived barriers to the development of small, medium and microenterprises: a case study of Thulamela Municipality in the Limpopo Province
}

\begin{abstract}
The study investigated the perceived barriers to the development of small, medium and microenterprises (SMMEs) operating in the South African small business sector. A quantitative orientation was used in carrying out the study through self-administered questionnaires and a descriptive quantitative method of analysis was applied. The research population consisted of entrepreneurs within the Thulamela Municipality in the Limpopo Province of South Africa. A purposive sample of seventy-five SMME owners and managers participated in this study $($ males $=73 \%, \mathrm{n}=55$; females $=27 \%, \mathrm{n}=20$ and, age range 18-55 years). The study seeks to add on the narrow body of literature concerning barriers faced by small, medium and microenterprises within the small business sector by revealing how SMMEs in South Africa are stalled from developing into successful enterprises as a result of some major barriers affecting the small business sector. The study revealed that, indeed, SMMEs in Thulamela Municipality in the Limpopo Province of South Africa are faced with various barriers affecting their development. Five significant barriers were identified, namely, lack of finance, access to market, out-dated equipment and technology, poor infrastructure and lack of training. The study recommends on the action plan that is required for SMMEs to increase their efficiency and sustaining themselves against possible barriers thereby helping entrepreneurs to exploit the full potential of the SMME sector.
\end{abstract}

Keywords: barriers, development, SMMEs, entrepreneurs, Thulamela municipality, South Africa.

JEL Classification: L26, P2.

\section{Introduction}

Globally, the small business sector is regarded as the engine of economic development. According to Worku (2016), the small, medium and microenterprise (SMME) sector has the ability to raise socio-economic encounters facing both developing and developed nations. Without entepreneurial development, it is argued that an economy weakens, levels of unemployment continue to escalate and the general standard of living deteriorates (Sachis, Segovia, Gill, Heras \& Villar, 2007, cited in Xing, Li, Bi, Wilamowska-Korsak, and Zhang, 2013). Small, medium and micro enterprises (SMMEs) are a major pillar of the economy in all countries within the development phase (AL-hyari, 2013). Thus, governments across the globe prioritize more on the development of the SMME sector to enhance development and growth of the economy.

A study by Govori (2013) revealed that the contributions of SMMEs to the creation of jobs and to poverty alleviation have been recognized by many developing countries and have been given prominence in many development plans such as the Local Economic Development (LED). The small business sector, which has had major Local

(c) Gift Donga, Hlanganipai Ngirande, Knowledge Shumba, 2016. Gift Donga, Student, Department of Business Management, University of Venda, South Africa.

Hlanganipai Ngirande, Lecturer, Department of Human Resource Management and Labour Relations, University of Venda, South Africa. Knowledge Shumba, Student, Department of Business Management, University of Venda, South Africa.
Economic Development successes globally, is, according to Malefane (2013), operating poorly in South Africa, when comparing with other nations in the same income category, namely, Thailand, Chile and Mexico. The matter concerning the development of SMMEs, therefore, needs to be prioritized in the South African economy. According to Thwala and Phaladi (2009, cited in Fatoki and Garwe, 2010 ), the government of South Africa has placed the development of SMME sector in the country and continuously thrives to maintain the sustainability of the SMME sector.

\section{Literature review}

The term SMME includes an extensive range of definitions. Organizations, as well as a number of countries, establish their definitive guidelines for categorizing SMMEs, often based on sales volume, number of employees, or the worth of assets (Govori, 2013). Govori (2013) defines SMMEs as enterprises with a maximum of 300 personnel, 15 million dollars in annual proceeds and 15 million dollars in assets. In the meantime, the European Union consider SMMEs as those that employ less than 250 personnel and which have a yearly turnover limited to EUR 50 million and an annual balance limited to 43 million euros.

The National Small Business Act of South Africa of 1996, as amended in 2003 (Government Gazette of the Republic of South Africa, 2003), on the other hand, defines an SMME as "a separate and distinct entity including cooperative enterprises and nongovernmental organizations managed by one owner 
or more, including its branches or subsidiaries, if any, is predominantly carried out in any sector or subsector of the economy mentioned in the schedule of size standards and can be classified as a SMME by satisfying the criteria mentioned in the schedule of size standards" (see Table 1). For the purpose of this study, the National Small Business Act of South Africa's definition of SMMEs was adopted.

Table 1. Quantitative definition of SMMEs in South Africa.

\begin{tabular}{|l|l|l|l|}
\hline \multicolumn{1}{|c|}{ Type of firm } & \multicolumn{1}{|c|}{ Employees } & \multicolumn{1}{c|}{ Turnover } & \multicolumn{1}{c|}{ Balance sheet } \\
\hline Small & $1-49$ & Maximum R13m & Maximum R5m \\
Medium & $51-200$ & Maximum R51m & Maximum R19m \\
\hline
\end{tabular}

Source: Fatoki and Garwe (2010).

According to Tlhomola (2011), SMMEs in South Africa, like any other developing economy, are expected to operate as the main force in both the social and economic change, also the SMMEs as enterprises have certain economic roles to fulfil. Within the first and second world countries, it is now generally accepted by policy makers internationally that SMMEs are fast becoming important in terms of occupation, wealth creation and the expansion of innovation (Oyelana and Adu, 2015).

Small, medium and micro enterprises as well contribute to a nation's gross domestic product (GDP) by either manufacturing products of value or through providing services to both consumers and/or other SMMEs (Small Business Development, 2012). There is some truth to the perception that SMMEs are primarily hawkers and small traders, since, in several countries, the majority of enterprises are engaged in commerce (Petrus, 2009). It is important to note, however, that in all countries, small manufacturing firms engaged in transformation activities are also an important component of SMME sector (Liedholm and Mead, 2012).

The small business sector, as highlighted earlier, plays an important role in the economy and, therefore, needs to be supported in order to increase the chances of success. In times of economic crisis, the existence of small, medium and microenterprises can stimulate the economy and hopefully improve the economies all around the world (Murphy, 2006, cited in Chimucheka, 2013). According to Florida (2014), when the best small firms become bigger, they spread good ideas across the entire economy and create lots of jobs through expansion. Despite the contribution the government and the private sector make towards economic and social stability, SMMEs are suffering a lot of challenges and barriers leading to their failures in developing (Tlhomola, 2011). In a similar view, Petrus (2009) points out that the failure rate of small business development in South Africa is phenomenal and much research is needed to unravel the causes contributing to such failures.

\section{Theoretical framework}

The study was guided by the Growth of the Firm theory postulated by Penrose (1959, cited in Lundvall, 2010). The theory offered some significant principles governing the growth and development of firms, as well as the rate at which firms can develop with success. Penrose claimed that firms are a mixture of both internal and external factors that help a firm to develop and to realize an economical advantage. As postulated by Penrose (1959, cited in Lundvall, 2010), the ignorance of these factors results in the failure, as well as loss of competitive advantage. The literature available also supports the theory of Growth of the Firm. According to Govori (2013), SMMEs are affected by the macroeconomic environment such as the political, economic, social, technological environmental, as well as some legal factors. Among the major external factors affecting the development and growth of SMMEs is lack of finance, not overlooking here the other factors such as competition, corruption government policies, crime and technology (Govori, 2013). On the other hand, Fatoki and Garwe (2010) argued that for new SMMEs to grow, it is of importance to reinforce not only the internal business environment, but also the external business environment.

\section{Problem statement}

Due to the growing recognition of the potential of SMMEs in job creation and the economic drive to South Africa, SMMEs are perceived as lagging behind in terms of knowledge, level of skills, investment in capital to sustain their activities, and access, as well as ability to take advantage of present technologies (Tlhomola, 2011). As in most countries, SMMEs find it challenging to acquire financing. Besides the lack of enough funding, the SMME sector seems to be lacking in efficient production technologies and information, scant use of management and control systems, inadequate consulting services and other related deficiencies (Demirbas, 2011).

Not much has been achieved in South Africa in the SMME sector towards its successful development as compared to same income earning countries due to limited research. Although, the South African government has tried to nurture a culture of entrepreneurship predominantly amongst black Africans, the victory of which could be ascertained by improved effectiveness in terms of growth turnover and job creation, which is not the case. 
Therefore, it is imperative to further explore the barriers to the development of small, medium and microenterprises in South Africa.

Throughout the 1990s and to date, most of the studies conducted on challenges or barriers faced by SMMEs in South Africa have mostly prioritized the urban set up whilst neglecting SMMEs within the rural or periurban set up (Fatoki and Garwe, 2010; Dinhucha Goncalves \& Jabbour, 2011), therefore, this study seeks to add on the narrow body of literature by closing the gap on an urban bias against SMMEs based in rural area, as well as small municipalities such as Thulamela Municipality in the Limpopo Province, one of the less developed provinces in South Africa. This was achieved by making a investigating on the barriers affecting the development of SMMEs in a peri-urban setting of the Thulamela Municipality.

\section{Research objectives}

The study aimed at investigating perceived barriers to the development of small, medium and microenterprises (SMMEs), as well as to determine measures that can be developed to successfully counteract the effects of barriers to the development of SMMEs) in the Thulamela Municipality, South Africa. To answer the study objective, the study was guided by the following research questions:

1. What can be perceived as barriers to the development of SMMEs in the Thulamela Municipality?

2. What measures can be developed to successfully counteract the effects of barriers to the development of SMMEs in the Thulamela Municipality?

\section{Methodology}

In order to ascertain the barriers affecting the development of SMMEs in the Thulamela municipality within the Limpopo Province in South Africa, an empirical survey, by means of a selfadministered semi structured questionnaire, was carried out among owners and managers of small, medium and microenterprises operating in the manufacturing and retail sector in the Thulamela Municipality.

The study was carried out in two stages, firstly by means of a pre-test which was carried out amongst 15 SMMEs in order to test the feasibility of the research questionnaire. The pre-test was also used to detect possible practical glitches in following the study procedure. For instance, glitches such as inappropriate recording, as well as response rates were to be ascertained and preventative procedures were developed. Thus, a lesser group of respondents similar to the target population was used. The research questionnaire was, then, administered to the pre-test respondents, in an identical manner as it was conducted in the main field work. The reliability $(0.845)$ of the final questionnaire was determined by means of the Cronbach Alpha. The pre-test familiarity was, then, used to improve the research instrument, research objectives as well as the research methodology for the main survey.

Seventy-five owners and managers from SMMEs within the Thulamela Municipality participated in this study (males $=73 \%, \mathrm{n}=55$; females $=27 \%, \mathrm{n}=$ 20 and, age range 18-55 years). Most of the respondents $(66.7 \% ; n=50)$ were both owners and managers of the enterprises and also the majority of respondents $(64.4 \% ; \mathrm{n}=49)$ operated for a period of between 1-5 years (see Table 2). Participants individually consented. They were assured of anonymity and confidentiality of the information to be obtained through a cover letter.

Table 2. Demographic characteristics of the respondents

\begin{tabular}{|l|l|c|c|}
\hline \multicolumn{1}{|c|}{ Variable } & \multicolumn{1}{|c|}{ Categories } & Frequency & Percentages (\%) \\
\hline \multirow{4}{*}{ Gender } & Female & 20 & 27 \\
\cline { 2 - 4 } & Male & 55 & 73 \\
\hline \multirow{5}{*}{ Age } & 25 years and below & 8 & 10.7 \\
\cline { 2 - 4 } & $26-35$ years & 30 & 40 \\
\cline { 2 - 5 } & $36-45$ years & 20 & 26.7 \\
\cline { 2 - 5 } & $46-55$ years & 10 & 13.3 \\
\cline { 2 - 5 } & $55+$ years & 7 & 9.3 \\
\hline \multirow{5}{*}{ Ownership } & Owner & 14 & 18.6 \\
\cline { 2 - 5 } & Manager & 11 & 14.7 \\
\cline { 2 - 5 } & Owner and manager & 50 & 66.7 \\
\hline \multirow{5}{*}{ Period of operation } & Less than 1 year & 8 & 11 \\
\cline { 2 - 5 } & $1-5$ years & 49 & 64.4 \\
\cline { 2 - 5 } & 6 years and above & 18 & 24.6 \\
\hline
\end{tabular}

\section{Data analysis}

The descriptive quantitative method of analysis was applied in the study. Content coding was firstly done to change the open responses of the participants to descriptive data. The main reason of the coding was to categorize responses into meaningful categories and, then, allocate frequencies to the responses. Ultimately, all the enumerated data were analyzed using Statistical Package for Social Sciences (SPSS) version 23.

\section{Results and discussion}

Five important areas were identified as the major barriers affecting the development of SMMEs in the Thulamela Municipality, namely lack of finance, access to market, out-dated equipment and technology, poor infrastructure and lack of training (see Table 3). 
Table 3. Barriers affecting development of SMMEs

\begin{tabular}{|l|c|c|c|c|c|c|}
\hline \multicolumn{1}{|c|}{ Description } & \multicolumn{2}{|c|}{ Agree } & \multicolumn{2}{c|}{ Neutral } & \multicolumn{2}{c|}{ Disagree } \\
\cline { 2 - 6 } & $f$ & $\%$ & $f$ & $\%$ & $f$ & 15 \\
\hline $\begin{array}{l}\text { Financing for work in progress and capital from finacial and non } \\
\text { financial institutions is a problem for SMMEs. }\end{array}$ & 64 & 85 & 0 & 0 & \multirow{2}{*}{3} & 35 \\
\hline $\begin{array}{l}\text { SMMEs access to market is limited due to stiffer competition from } \\
\text { established businesses. }\end{array}$ & 49 & 65 & 0 & 0 & 26 & 30 \\
\hline $\begin{array}{l}\text { Access to appropriate technology still remains a challenge for some } \\
\text { entrepreneurs. }\end{array}$ & 45 & 60 & 0 & 0 & 30 \\
\hline $\begin{array}{l}\text { Entrepreneurs dont receive some training on starting a business or } \\
\text { general business management prior to establishment. }\end{array}$ & 53 & 70 & 0 & 0 & 22 & 30 \\
\hline The infrastructure currently available is in bad condition. & 41 & 55 & 0 & 0 & 34 & 45 \\
\hline
\end{tabular}

Results in Table 3 show that lack of finance is the major barrier affecting development of SMMEs within the South African small business sector. The respondents $(85 \% ; n=64)$ were of the same opinion that financing for both work in progress and capital is a challenge for SMMEs. The respondents beleived that the policies are discrimatory and do not properly accomodate the SMMEs, a fragmented sector which was historically disadvantaged.

The results also show that access to market acts as a significant barrier to the development of SMMEs. The respondents $(65 \% ; n=49)$ indicated that they faced a stiffer competition in the market environment due to already established enterprises and, in turn, acquiring a less market share. The results further revealed that most of the SMMEs operating in South Africa are operating marginally due to stiffer competition, as respondents indicated that they are failing to access space in the Central Business District (CBD).

With regard to the importance of technology towards the development of the small business sector, most respondents indicated that, whereas technology is rated as unavoidable for increased profitability, access to appropriate technology still remains a problem for some entrepreneurs. Majority $(60 \% ; \mathrm{n}=45)$ of SMMEs pointed out that they could not get new equipment and technology due to either inadequate resources or knowledge.

The majority of entrepreneurs in South Africa do not receive training before establishing their small businesses as evidenced in the study. The enterpreneurs $(70 \% ; \mathrm{n}=53)$ indicated that they did not have any formal training on starting a business or general business management prior to establishment. This was evidenced by lack of financal management, unavailability of business plans and inapropriate human resource engagements. However, even though the majority of entrepreneurs were untrained, they strongly believed that training is an important factor in driving small business growth.

It is clear in the study that the infrastructure being utilized by most SMMEs in South Africa is poor. Fifty-five percent of the SMMEs indicated that most of the premises they are operating from are not up to expected standards. The majority of the respondents $(80 \% ; n=60)$ indicated that they do not even own the premises. The results further revealed that some of the SMMEs $(10 \% ; \mathrm{n}=7)$ operate in unauthorized premises and have had constant clashes with the responsible local authorities (see Table 4). Given this, one can argue that infrastucture is a barrier to SMMEs development.

Table 4. Variation of premises ownership

\begin{tabular}{|l|c|c|}
\hline \multicolumn{1}{|c|}{ Description } & $f$ & $\%$ \\
\hline Own premises & 15 & 20 \\
\hline Rented & 53 & 70 \\
\hline Unauthorized premises & 7 & 10 \\
\hline Total & 75 & 100 \\
\hline
\end{tabular}

Furthermore, the study probed into problems affecting the small business sector in acquiring finance and these were lack of collateral security, insufficient credit records, lack of tax records, unregesterd businesses and failure to draft proper business plans (see Table 5).

Table 5. Barriers to accessing finance

\begin{tabular}{|l|c|c|c|c|c|c|}
\hline \multicolumn{1}{|c|}{ Description } & \multicolumn{2}{c|}{ Agree } & \multicolumn{2}{c|}{ Neutral } & \multicolumn{2}{c|}{ Disagree } \\
\cline { 2 - 7 } & \multicolumn{2}{|c|}{$f \%$} & \multicolumn{2}{c|}{$f \%$} & 11 & 15 \\
\hline $\begin{array}{l}\text { Financial institutions are not willing to extend loans to } \\
\text { entrepreneurs without business plans }\end{array}$ & 60 & 80 & 4 & 5 & 0 & 26 \\
\hline Unregestered SMMEs are not recognised by financial institutions & 49 & 65 & 0 & 0 & 24 & 35 \\
\hline $\begin{array}{l}\text { Lack of collaterial negatively affects SMMEs in acquiring work in } \\
\text { progress and start up capital from financial institutions }\end{array}$ & 51 & 68 & 0 & 0 & 17 & 22 \\
\hline Financial institution do not trust SMMEs with poor credit records & 56 & 75 & 2 & 3 & 32 & 30 \\
\hline $\begin{array}{l}\text { SMMEs should have proper tax records inorder to acquire loans } \\
\text { from financial institution }\end{array}$ & 53 & 70 & 0 & 0 & 32 \\
\hline
\end{tabular}


For the purpose of comparing and measuring the weight of these barriers towards the development of SMMEs, the barriers were ranked according to the descending order. Results in Table 6 show that access to finance was considered by the majority of respondents $(85 \% ; n=64)$ as the main barrier for SMMEs and, as a result, it is ranked on the first position. At the bottom, on the fifth position was poor infrastructure, with the least number of respondents stats $(55 \% ; n=41)$ who perceived poor infrastructure as having less negative impact on the development of SMMEs.

Table 6. Ranking of barriers to development of SMMEs

\begin{tabular}{|l|c|c|c|}
\hline \multirow{2}{*}{\multicolumn{1}{|c|}{ Description }} & \multicolumn{2}{|c|}{ Respondents } & \\
\cline { 2 - 4 } & $f$ & $\%$ & rank \\
\hline Poor infrastructure & 41 & 55 & 5 \\
\hline $\begin{array}{l}\text { Outdated equipment and } \\
\text { technology }\end{array}$ & 45 & 60 & 4 \\
\hline Access to market & 49 & 65 & 3 \\
\hline Lack of training & 53 & 70 & 2 \\
\hline Lack of finance & 64 & 85 & 1 \\
\hline
\end{tabular}

\section{Conclusions and recomendations}

The findings of the study are particularly significant to entrepreneurs. Most importantly, the results provide a clear understanding to the entrepreneurs of the significant barriers which influence the development of their enterprises. Despite the vital role of SMMEs in creating an economic private sector and significantly contributing to employment creation, innovation, in addition to the development of the economy in general, SMMEs are facing more difficulties around the globe and within developing nations in particular. Likewise, South African SMMEs are disadvantaged by a number of barriers, which may vary from regions within the country or amongst specific SMMEs. Nevertheless, there are certain barriers that are mutual to nearly all SMMEs. The study revealed that lack of finance, poor infrastructure, lack of training, access to the market, as well as outdated equipment and technology are the key enterprise barriers affecting the development of South African SMMEs.

As a result of the findings from the study, the following recommendations are made:

The main small business sector development necessity of SMMEs operating in South Africa is finance. In the course of the survey, it was recognized that most SMMEs are functioning on a tight budget, in turn, this is negatively disturbing their management of cash, as well as development opportunities. Khula Enterprise, which is aimed at improving small businesses access to finance should establish dedicated lines of credit specifically meant for SMMEs. This can be realized through forming partnerships with other gorvenment departments, as well as the private sector. Bilateral cooperation should be undertaken between the local municipalities, private institutions and entrepreneurs for the purpose of encouraging a culture of entrepreneurship through cooperation amongst schools and SMMEs, such as expanding the number of internships for students in SMMEs and supporting the creation of business incubators within tertiary institutions.

Local Further Education Training (FET) colleges also need to be established in order to improve appropriate short courses for entrepreneurs. The courses might include the idea of multi-skilling, where one entrepreneur can conduct a number of actions such as basic book keeping and general management. The short courses may also embrace preparing business plans, which was revealed as the main scarcity faced by entrepreneurs in acquiring financial loans. These approaches, if applied, are likely to reduce the costs of operating for SMMEs, thus, enhancing both their profitability and sustainability.

Lastly, policy makers within the government can improve the legislative and regulatory framework for the establishment and development SMME by designing measures in accordance to the "Think Small First" policy which implies that policy makers should provide full attention to SMMEs at an early development stage, in addition, strategies to encourage SMMEs need to be tailored to each sector. The government can also establish Special Economic Zones (SEZs), with various preferential treatments designed for SMMEs, governed by a comprehensive and integrated set of laws and regulations. SEZs can establish a conjusive investment environment and provide good quality, as well as effective infrastructure.

\section{Limitations and future research}

The evidence reported in this study should be interpreted in the light of several limitations. The study results are constrained by the fact that the study only investigated some of the barriers that affect successful entrepreneurship development, in a relatively small sample of participants within one municipality across the Limpopo Province, making it difficult to generalize the results. Also, with such a limited number of questions, it is not possible to fully evaluate the origin of a given barrier, nor to test the implications of a barrier on another. Lastly not all the barriers that may affect the development of SMMEs in the Thulamela Municipality were examined, and there might be other factors. Therefore, more future comprehensive research is still required to clarify other underlying dimensions that affect SMME businesses such as the owner's managerial skills set, business strategy variables and organizational structures. 


\section{References}

1. Al-Hyari, K. (2013). Identification of Barrier Factors and Potential Solutions to SMEs Development among Jordanian Manufacturing Sector, International Journal of Business and Management, 8 (24), p. 132.

2. Chimucheka, T. (2013). Overview and performance of the SMMEs sector in South Africa, Mediterranean Journal of Social Sciences, 4 (14), p. 783.

3. Demirbas, D. (2011). Formal, informal, environment and skill Barriers for entrepreneurs: Microeconometric evidence from 197 Turkish SMEs, Journal of Business and Policy Research, 6 (2), pp. 13-35.

4. Dinhucha Gonçalves Fumo, N. and Jose Chiappetta Jabbour, C. (2011). Barriers faced by MSEs: evidence from Mozambique, Industrial Management \& Data Systems, 111 (6), pp. 849-868.

5. Government Gazette of the Republic of South Africa. (2003). National Small Business Amendment Act. Available at: http//www.info.gov.za/gazette/acts/2003/a26-03/pdf.

6. Fatoki, O. \& Garwe, D. (2010). Obstacles to the growth of new SMEs in South Africa: A principle component analysis approach, African journal of business and management, 4 (5), pp. 729-738.

7. Florida, R. (2014). The Rise of the Creative Class-Revisited: Revised and Expanded. USA: Basic books.

8. Govori, A. (2013). Analysis of external factors affecting the development of SMMEs in Kosovo. Kosovo: MPRA.

9. Liedholm, C. \& Mead, C. (2012). Small Enterprise and Economic Development. New York: Routledge.

10. Lundvall, B.A. (2010). National systems of innovation: Toward a theory of innovation and interactive learning (Vol. 2). Anthem Press.

11. Malefane, S.R. (2013). Small Medium, and Micro Enterprise and local economic-base restructuring: a South African local government perspective, Journal of Public Administration, 48 (4), pp. 671-690.

12. Oyelana, A.A. and Adu, E.O. (2015). Small and Medium Enterprises (SMEs) as a Means of Creating Employment and Poverty Reduction in Fort Beaufort, Eastern Cape Province of South Africa, Journal of Social Sciences, 45 (1), pp. 8-15.

13. Petrus, W. (2009). Enterprise Governance and Enterprise Engineering. Netherlands: Soget Nederland.

14. Small Business Development. (2012). Available at: http://www.etu.org.za.

15. Tlhomola, S. (2011). A research paper on: Perceptions of Small, Medium and Micro Enterprise Entrepreneur regarding Factors Contributing to Failure: A Case ofTshwane Metropolitan Municipality. Unpublished research paper at Tshwane University.

16. Worku, Z, (2016). Barriers to the growth of small, micro and medium-sized business enterprises in the Vaal Triangle region of South Africa, African Journal of Science, Technology, Innovation and Development, 8 (2), pp. 134-141.

17. Xing, Y., Li, L., Bi, Z., Wilamowska-Korsak, M. and Zhang, L. (2013). Operations research (OR) in service industries: a comprehensive review, Systems Research and Behavioral Science, 30 (3), pp. 300-353. 